\title{
ROAD INFRASTRUCTURE AND SPATIAL ECONOMIC DEPENDENCE IN THE WESTERN REGION OF JAVA
}

\author{
Siti Herni Rochana \\ Institut Teknologi Bandung \\ (siti_hr@sappk.itb.ac.id) \\ B. Kombaitan \\ Institut Teknologi Bandung \\ (benk@pl.tb.ac.id) \\ Eka Purwanda \\ STIE STEMBI Bandung \\ (purwandaeka@yahoo.com)
}

\begin{abstract}
The western region of the island of Java consists of three provinces, namely: West Java, Banten, and Jakarta, is a region that contributes significantly to the GDP of Indonesia. In 2010 the contribution of the three provinces was 33.94\% of the total GDP, and the remaining $66.06 \%$ came from the other 30 provinces. In spite of its high contribution, in terms of the value added by the western region of Java, there are inequalities between the regions. In the year 2010, Jakarta's per capita income was ten times, or more, than that of Lebak. The existence of this problem in the income disparity between the regions in western Java raises questions relating to the spatial economic dependence of the western region of Java. The unit analysis of the research is all the districts/cities in West Java, Banten, and Jakarta. The measurement used for the spatial economic dependence is Moran's Index. Spatial variables were comprised in the spatial weight matrix (matrix-W), which was formed using three approaches: based on the distance, the neighbourhood, and the road transportation network. The economic variables in this study are the level of income per capita and economic growth. The results showed spatial economic dependence, based on distance and neighbourhood, tended to be low. Whereas, the spatial economic dependence based on road connectivity, especially freeways, showed a moderate correlation.
\end{abstract}

Keywords: road infrastructure, spatial economic dependence, Moran's Index, western region of Java.

\section{INTRODUCTION}

West Java, Banten, and Jakarta are provinces producing high added value in Indonesia. The contribution of the three provinces to Indonesia's GDP is quite large (Figure 1). The GDP of West Java, Banten, and Jakarta in 2010 were IDR308.96 trillion, IDR83.80 trillion and IDR391.53 trillion respectively. These figures represent the percentage proportions $13.37 \%$, $3.63 \%$, and $16.94 \%$ of Indonesia's GDP respectively. The total GDP contribution given by the three provinces was $33.94 \%$, with the remaining $66.06 \%$ coming from the other 30 provinces. The high GDP generated from these three prov- inces shows that the three provinces have high intensity economic activities. This is not surprising because the country's capital Jakarta is the centre for government and business, while West Java and Banten are districts/cities adjacent to Jakarta.

Behind the high output in West Java, Banten, and Jakarta, there are inequalities between the districts/cities. In 2010, based on current prices, the level of income per capita of DKI Jakarta was the highest at IDR89.92 million, while the lowest income per capita was in Lebak regency at the level of IDR6.45 million. Given these figures, it can be said that the level of income per 
capita of Jakarta was about 14 times that of Lebak. Large differences in the per capita income levels of the two areas show that the disparities between the regions are quite striking. This example of inter-regional income disparities between Jakarta and Lebak raises great concerns because the geographical distance between the two areas is not so far. The distance between Jakarta and Lebak is approximately 131 kilometers. The per capita income gap between the regions in the study area showed the presence of a regional income disparity problem.

Theoretically, spatial economic relations can be explained from the theory of trade and economic geography. Dixit and Norman (1980) stated that the areas having trade relations tend to have the same relative prices for goods and factors of production, including wages. Because wages are a source of income, it can be said that in areas that have trade relations, then incomes should be relatively equal in those areas.

The new economic geography (Fujita et al., 1999) stated that inter-regional trade will occur if transportation costs are low enough so that the inter-regional trade is economically feasible. Transportation costs are the determining factor for trade relations. If the transportation costs are too expensive, then trade is not economically feasible. If the transportation costs are low, then trade will be economically feasible. Transport costs are very closely related to infrastructure, particularly the roads. Good infrastructure for transport will cause low transportation costs. Conversely, poor infrastructure causes high transportation costs.

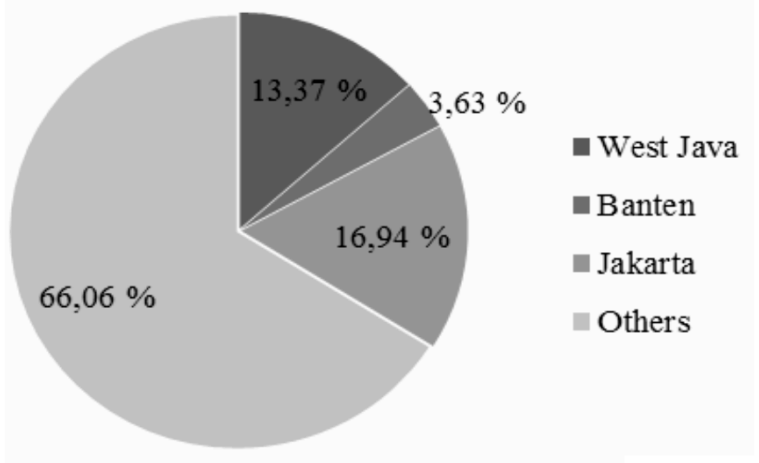

Source: Statistics Indonesia

Figure 1. GRDP contribution of West Java, Banten, and Jakarta to Indonesia's GDP in 2010
The problem of the regional income disparity in the western region of Java raises a question about connectivity and trade relationships. If the transportation accessibility links among the regions are available equally in all directions, the difference in the revenues of adjacent regions should not be great. The income gap between the regions of West Java, Banten, and Jakarta raises many questions relating to economic dependencies (trade relations) and inter-regional transport connectivity in the western region of Java.

\section{THEORETICAL FRAMEWORK}

The economic theory that explains the effect of road infrastructure on economic spatial dependence can be seen in Figure 2. Road infrastructure can reduce transportation costs. The new economic geography theory (Krugman, 1991; Fujita et. al., 1999) explains that a low cost for transportation will create and establish trade relations between regions. Trade between regions would then equalize the price of the factors of production, including wages and interest rates. The factor of price equalization can lead to spatial economic dependency.

\section{Transportation Costs and Trade}

The new economic geography was formed by Krugman (1991) and then Fujita et. al. (1999). This theory explains the connection between transportation costs and trade relations. Low transportation costs can create trade relations and form an agglomeration built core and also periphery formations. Conversely, high transportation costs can impede trade relations so that regions will produce goods in an autarky manner.

Consumer utility is a function of the quantity of goods manufacturing (M) and agricultural goods (A) in the form:

$$
U=M^{\mu} A^{1-\mu}
$$

where $0<\mu<1$. Manufactured goods will vary in a condition of increasing returns in a monopolistic competition. The production of manufactured goods follows the equation: 


$$
M=\left[\int_{0}^{n} m(i)^{\rho} d i\right]^{1 / \rho}, \quad 0<\rho<1
$$

While the budgetary constraints faced by consumers are:

$$
Y=p^{A} A+\int_{0}^{n} p(i) m(i) d i
$$

From the results of the consumers' optimization, the demand functions for manufactured goods and agriculture goods are:

$$
\begin{aligned}
& m(j)=\mu Y \frac{p(j)^{-\sigma}}{G^{-(\sigma-1)}} \text { for } j \in[0, n] \\
& A=\frac{(1-\mu) Y}{p^{A}}
\end{aligned}
$$

By entering the manufacturing demand function (2) and agriculture (3) into the utility function resulting from the indirect utility function as follows, we get:

$$
U=\mu^{\mu}(1-\mu)^{(1-\mu)} Y G^{-\mu}\left(p^{A}\right)^{-(1-\mu)}
$$

Where $G^{\mu}\left(p^{A}\right)^{(1-\mu)}$ is the cost of living index. Equation (4) shows that consumer utility is affected by the price index. The form of the transportation costs in the core periphery models is iceberg where transportation costs are entered as a multiplier of the home price. As an example, if the price of goods produced in the North is $p_{r}^{M}$, and the transportation costs from North to South is $T_{r s}^{M}$, then the price of goods delivered to the South will be

$$
p_{r s}^{M}=p_{r}^{M} T_{r s}^{M}
$$

By including the transportation costs (5), the demand function for manufactured goods is:

$$
q_{r}^{M}=\mu \sum_{s=1}^{R} Y_{s}\left(p_{r}^{M} T_{r s}^{M}\right)^{-\sigma} G_{s}^{\sigma-1} T_{r s}^{M}
$$

On the other hand, companies use the fixed labour input $\mathrm{F}$ and marginal imput $C^{M}$ so that the amount of labour used is shown in the following equation:

$$
l^{M}=F+c^{M} q^{M}
$$

The profit function is revenue from the sale of manufactured goods, minus the cost of labour: $\pi_{r}=p_{r}^{M} q_{r}^{M}-w_{r}^{M}\left(F+c^{M} q_{r}^{M}\right)$. The profit maximization is obtained from:

$$
p_{r}^{M}=c^{M} w_{r}^{M} / \rho
$$

By entering the price equation (7) into the profit function:

$$
\pi_{r}=w_{r}^{M}\left[\frac{q_{r}^{M} c^{M}}{\sigma-1}-F\right]
$$

The balance of the manufacturer (at the zero profit condition) is obtained:

$$
\begin{aligned}
& q^{*} \equiv F(\sigma-1) / c^{M} \\
& l^{*} \equiv F+c^{M} q^{*}=F \sigma
\end{aligned}
$$

Using the price equation (7), it can also be found that the wage of manufacturing workers in the North is as follows:

$$
\left.w_{r}^{M}=\left[\sum_{s=1}^{R} Y_{s}\left(T_{r s}^{M}\right)^{1-\sigma} G_{s}^{\sigma-1}\right]^{1 / \sigma}\right]
$$

\section{Trade and Factor Price Equalization}

Dixit and Norman (1980) built a proposition that trade would make the factor price equalization. Suppose a country produces goods named 1 and 2, respectively priced at $p_{1}^{a}$ and $p_{2}^{a}$ under the condition of autarky and $p_{1}$ and $p_{2}$ under the condition of balanced trade. While the imports for the two goods are $m_{1}$ and $m_{2}$. The feasible condition for trade is therefore:

$$
\left(p_{1}^{a}-p_{1}\right) m_{1}+\left(p_{2}^{a}-p_{2}\right) m_{2} \geq 0
$$

The prices of the goods are a reflection of the wages, which can be written as follows:

$$
\begin{aligned}
& p_{1}=b_{11} w_{1}+b_{12} w_{2} \\
& p_{2}=b_{21} w_{1}+b_{22} w_{2}
\end{aligned}
$$

Where $b_{i j}$ is the input coefficient denoting the amount of factor $j$ required for a unit output of good $i$. The output price ratio can be written as: 


$$
\frac{p_{1}}{p_{2}}=\frac{b_{11} w_{1}+b_{12} w_{2}}{b_{21} w_{1}+b_{22} w_{2}}
$$

Defining the relative output price as $\pi=p_{1} / p_{2}$ and the relative factor price as $w=w_{1} / w_{2}$, the equation for $\pi$ is :

$$
\pi=\left(b_{11} w+b_{12}\right) /\left(b_{21} w+b_{22}\right)
$$

Changes in the relative output prices resulting from changes in the relative factor prices can be described as follows:

$$
\begin{aligned}
\frac{1}{\pi} \frac{d \pi}{d w} & =\frac{b_{11}}{b_{11} w+b_{12}}-\frac{b_{21}}{b_{21} w+b_{22}} \\
& =\frac{1}{w+b_{12} / b_{11}}-\frac{1}{w+b_{22} / b_{21}} \\
& =\frac{b_{22} / b_{21}-b_{12} / b_{11}}{\left(w+b_{12} / b_{11}\right)\left(w+b_{22} / b_{21}\right)}
\end{aligned}
$$

Equation (17) shows that changes in the relative factor prices will lead to changes in the relative output prices if the ratio of the input coefficient is different.

\section{Hypotheses}

A study of the available literature showed that low transportation costs will encourage trade relations, and further equalize the relative wages. The development of adequate transport infrastructure will decrease transportation costs. Thus this can be arranged in a hypothesis that the regions linked by sufficient transport infrastructure will have an economic dependence.

\section{METHODOLOGY}

\section{Data}

The observation area covered all the districts/cities in West Java, Banten, and DKI Jakarta. In West Java there are 17 districts and 9 cities. The province of Banten consists of 4 districts and 4 cities. While in this study Jakarta is treated as one region. The year of observation in this study was 2010 .

\section{Spatial Dependence Measurement}

Measurement of the spatial economic dependence is done using Moran's Index. Princi- pally, Moran's Index is a modified form of correlation between the economic variables and the spatial variables. The formula for Moran's Index (Fischer and Wang, 2011) is as follows:

$$
I=\frac{n}{W_{0}} \frac{\sum_{i=1}^{n} \cdot \sum_{j=1}^{n} W_{i j}\left(y_{i}-\bar{y}\right)\left(y_{j}-\bar{y}\right)}{\sum_{i=1}^{n}(y-\overline{\bar{y}})^{2}}
$$

Where:

$$
W_{0}=\sum_{i=1}^{n} \cdot \sum_{j \neq i}^{n} W_{i j}
$$

$y_{i}$ : economic variables (income, growth) $\mathrm{i}$

$\bar{y} \quad$ : average of the economic variables

$w_{i j}$ : spatial weight matrix

$i \quad:$ districts/cities $\mathrm{i}$

$j \quad:$ districts/cities $\mathrm{j}$

The range value of Moran's Index is $-1 \leq \mathrm{I} \leq$ 1. A Moran's Index value of +1 indicates a perfect correlation, while the value -1 indicates a perfect dispersion. The value 0 indicates no correlation. Expected values and variations for Moran's Index are:

$$
\begin{aligned}
& E(I)=-\frac{1}{(n-1)} \\
& \operatorname{Var}(I)=\frac{n^{2}(n-1) W_{1}-n(n-1) W_{2}-2 W_{0}^{2}}{(n+1)(n-1)^{2} W_{0}^{2}}
\end{aligned}
$$

Where :

$$
\begin{aligned}
& W_{0}=\sum_{i=1}^{n} \cdot \sum_{j \neq i}^{n} W_{i j} \\
& W_{1}=\frac{1}{2} \sum_{i=1}^{n} \cdot \sum_{j \neq i}^{n}\left(W_{i j}+W_{j i}\right)^{2} \\
& W_{2}=\sum_{k=1}^{n} \cdot\left(\sum_{j=1}^{n} W_{k j}+\sum_{i=1}^{n} W_{i k}\right)^{2}
\end{aligned}
$$

\section{Spatial Weight Matrix Specification}

Measurement of the spatial dependencies can be done using correlation or regression. However, the spatial correlation or regression is done by inserting a spatial variable. The spatial variable is captured in the spatial weight matrix or the so-called matrix-W. In principle, there are two stages in the formation of matrix-W: forming the matrix-C (spatial contiguity matrix), then form- 
ing a matrix-W (Anselin, 1988; Chen, 2012). Formation of the matrix-W can be described as follows:

Spatial weight matrix:

$$
W=\frac{C}{C_{0}}\left[\begin{array}{cccc}
w_{11} & w_{12} & \ldots & w_{1 n} \\
w_{21} & w_{22} & \ldots & w_{2 n} \\
\vdots & \vdots & \ddots & \vdots \\
w_{n 1} & w_{n 2} & \ldots & w_{n n}
\end{array}\right]
$$

Spatial contiguity matrix:

$$
C=\left[\begin{array}{cccc}
c_{11} & c_{12} & \ldots & c_{1 n} \\
c_{21} & c_{22} & \ldots & c_{2 n} \\
\vdots & \vdots & \ddots & \vdots \\
c_{n 1} & c_{n 2} & \ldots & c_{n n}
\end{array}\right]
$$

Where:

$$
C_{0}=\sum_{i=1}^{n} \cdot \sum_{j=1}^{n} c_{i j}, \quad \sum_{i=1}^{n} \cdot \sum_{j=1}^{n} w_{i j}=1
$$

In the formation of matrix-C, there are several methods that can be used. In this study, matrix-C was built using three approaches: based on distance, based on adjacent territories (neighbours), and based on the road transportation network:

1. Spatial contiguity matrix based on distance.

The formation of matrix- $\mathrm{W}$ is usually made based on distance. This formation starts with making a matrix-C, which has elements of the distance decay. This distance decay is the inverse distance or inverse distance squared (Anselin, 2003).

2. Spatial contiguity matrix based on neighbourhoods.

Matrix-W can also be made using the neighbourhood approach. In this case, matrix-W's formation starts with building matrix-C, which contains weighted elements. The weights are valued as 1 for the adjacent areas and 0 for the other areas (LeSage, 1997).

3. Spatial contiguity matrix based on the transportation network.

\section{a. Freeway}

Recently, matrix-W was also developed to be able to capture the transportation network. In this study, matrix-W was built from matrix-C which had weighted elements based on freeways.

\section{b. Ordinary Roads}

Besides capturing freeways, matrix- $\mathrm{W}$ also captured ordinary roads as indicators of the connectivity among the districts/cities.

The operationalisation of the variables in this

\begin{tabular}{|c|c|c|c|c|c|}
\hline No. & Variables & Notation & Indicators & Measurement & Units \\
\hline 1 & Income & $\mathrm{y}_{1}$ & Per capita output & $\frac{\text { GRDP }}{\text { Population }}$ & Rp/person \\
\hline 2 & Economic Growth & $\mathrm{y}_{2}$ & $\begin{array}{l}\text { Growth of per capita } \\
\text { output }\end{array}$ & $\frac{\text { PCGRDPt-PCGRDPt-1 }}{\text { PCGRDPt-1 }}$ & Percent \\
\hline 3 & Distance & d & Distance & $\begin{array}{l}\text { Distance between } \\
\text { regions }\end{array}$ & Kilometers \\
\hline 4 & Neighbour & $\mathrm{b}$ & $\begin{array}{l}\text { Regions that are } \\
\text { adjacent to each other }\end{array}$ & $\begin{array}{l}\mathrm{cij}=1, \text { if regions were adjacent } \\
\mathrm{cij}=0, \text { other }\end{array}$ & \\
\hline 5 & Road 1 (freeway) & $\mathrm{r}_{1}$ & $\begin{array}{l}\text { Regions connected by } \\
\text { freeways }\end{array}$ & $\begin{array}{l}\mathrm{cij}=1, \text { if regions were connected } \\
\text { by freeways } \\
\text { cij }=0 \text {, others }\end{array}$ & \\
\hline 6 & Road 2 (ordinary) & $\mathrm{r}_{2}$ & $\begin{array}{l}\text { Regions connected by } \\
\text { non-freeways }\end{array}$ & $\begin{array}{l}\text { cij be weighted based on the type } \\
\text { of roads }\end{array}$ & \\
\hline
\end{tabular}
study is shown in Table 1.

Table 1. Operationalisaton of variables

Annotation: GRDP = Gross Regional Domestic Product; PCGRDP = Per Capita Gross Regional Domestic Product 


\section{RESULT}

Figure 2 is a map of West Java which describes the distribution of per capita income. Districts/cities with dark colours show a higher per capita income. Jakarta has the highest per capita income with IDR89.9 million per capita per year, while the lowest is Lebak, which only has IDR6.5 million per capita per year.

This description of the income distribution, with Jakarta having the highest rank is not surprising, because Jakarta is the capital and the largest business centre in Indonesia. On the other hand, Lebak has the lowest per capita income. This finding is quite odd, because Lebak is located not that far away from Jakarta (about 131 kilometers away). This relatively small distance between both cities should not result in so big a difference between their per capita income levels.

Figure 3 shows the economic growth of the districts/cities in the western region of Java. The districts/cities having higher economic growth are shown by their increasingly intense colour. Karawang has the highest economic growth, with a growth rate of $18.19 \%$, while Tasikmalaya has the lowest economic growth, at a growth rate of only $6.21 \%$.

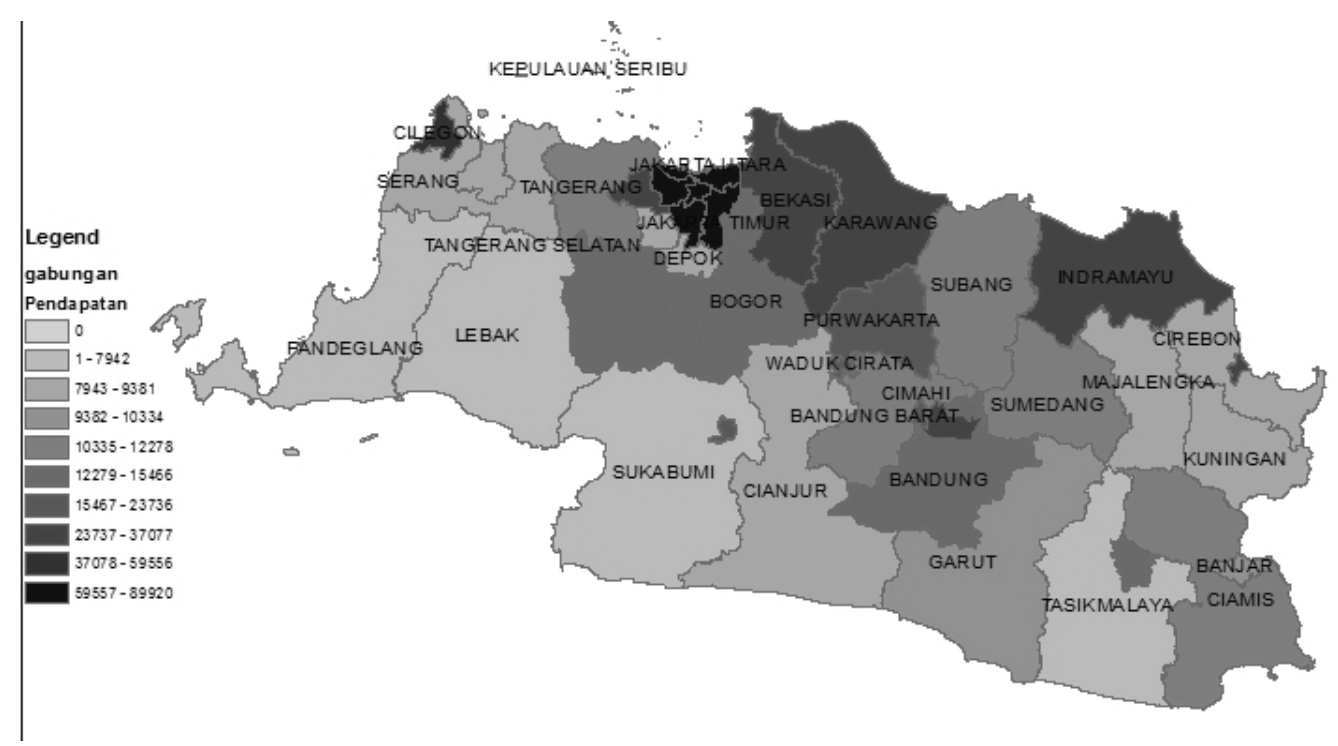

Figure 2. Income per capita of the districts/cities in the western region of java

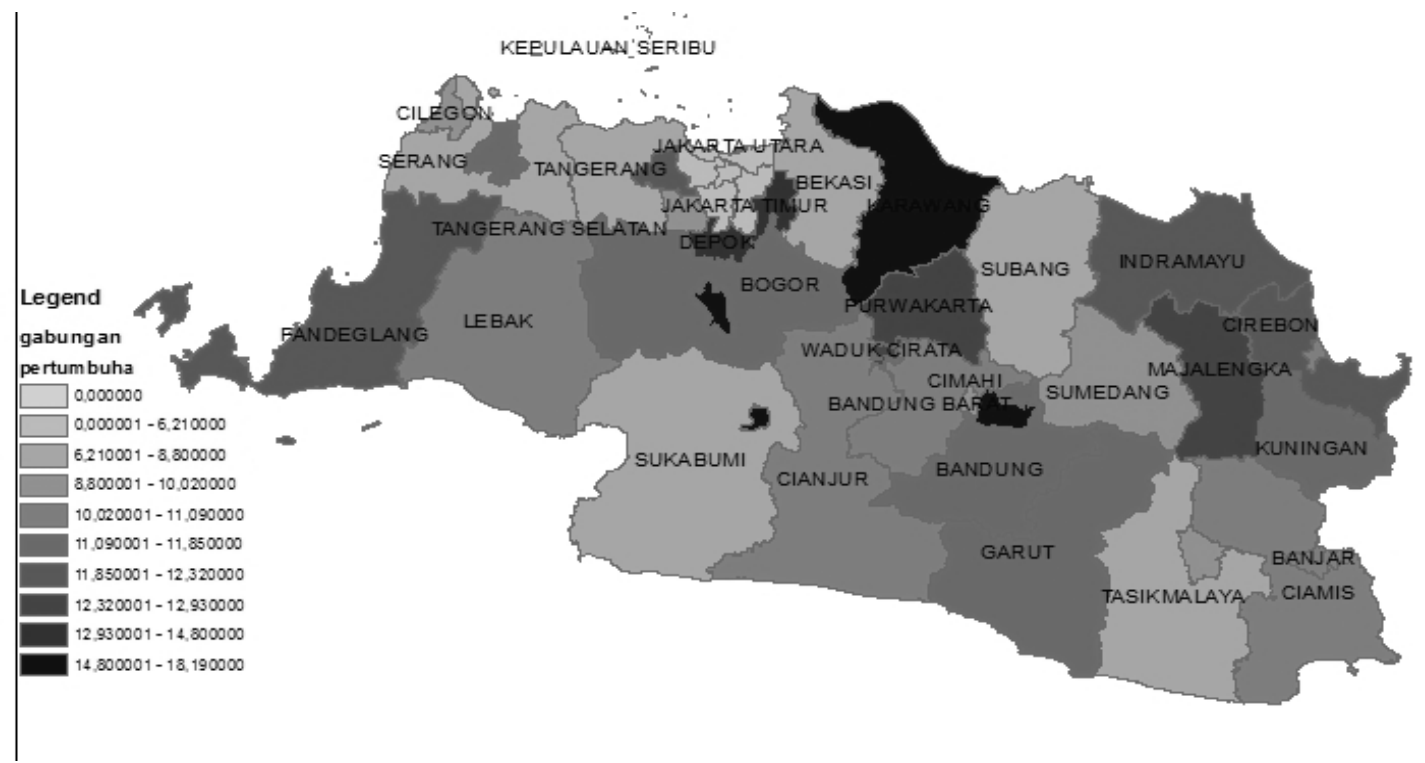

Figure 3. Economic growth of the districts/cities in the western region of java 
Karawang is the centre for industrial activity. The high economic growth in Karawang is caused by the encouragement given to industrial activity in the region. Tasikmalaya is an agricultural area, whose low economic growth could be caused by the slow growth in the agricultural sector in this region.

Moran's Index value for each matrix-W on income and economic growth can be seen in Table 2. From Table 2 we find three significant Moran's Index values for income dependence: that based on the distance between regions is 0.01763 , the income dependency based on the connectivity of ordinary roads is 0.0628 , and the dependency of economic growth based on the freeways' connectivity is moderate at 0.2260 .

Of the three significant Moran's Index values, two of the values are very low, 0.01763 for the income dependencies based on distance and 0.0628 for the income dependencies based on ordinary roads' connectivity. A low value for Moran's Index indicates that the relationship of the income among regions based on distance and ordinary roads is very small. An increased income from an area is associated with the increased income in other regions, but the correlation is very small.

This finding is similar to a study in China. Ho and Li (2010) found that there was no absolute convergence across cities during the period 1984-2003. They found that cities with a comparable per capita GDP level were likely to be located in the same region; further, cities tend to mirror the mobility of their counterparts located within the same province.

Referring to classical economics, income levels are determined more by the initial income. The findings in this research, that distance and ordinary roads correlated with income levels, requires further research to test the spatial econometric method by adding other explanatory variables such as the level of initial income.

From Table 2 the high value and significance of the Moran's Index for dependencies of economic growth among areas linked by freeways can also be seen, with a value of 0.2260 . This value illustrates that, among areas connected by freeways, they have a high degree of interdependency in their economic growth. A high relationship of interdependencies in economic growth among the regions indicates that the economy is interrelated. Specifically, the relationship in question is the one for economic trade.

Table 2. Moran's index value for spatial economic dependence in the western region of java

\begin{tabular}{lll}
\hline \multirow{2}{*}{ Matrix-W } & \multicolumn{2}{c}{ Economic Variables } \\
\cline { 2 - 3 } & \multicolumn{1}{c}{ Income } & \multicolumn{1}{c}{ Growth } \\
\cline { 2 - 3 } Distance & 0.01763 & -0.0276 \\
& $(2.9675)^{* *}$ & $(0.2731)$ \\
Neighbour & 0,0798 & -0.2067 \\
& $(0.8555)$ & $(-1.0329)$ \\
Road-1 (freeway) & 0.1546 & 0.2260 \\
& $(1.0915)$ & $(1.4721)^{*}$ \\
Road-2 (ordinary & 0.0628 & 0.0899 \\
road) & $(10.4089)^{* * *}$ & $(0)$ \\
\hline ***,*** are significant at $\alpha=0.1, \alpha=0.05$, and $\alpha=0.01 ; \mathrm{z}-$ \\
statistic in parentheses
\end{tabular}

Back to the new economic geography theory, inter-regions would have trade relations if the transportation costs were lower and vice versa. The observation by Moran's Index indicates that the regions linked by freeways have a high economic dependency. This occurs because the areas connected by freeways have lower transport costs than areas that are not connected by freeways. Lower transport costs lead to the trade between regions becoming economically feasible.

Moran's Index for economic growth dependencies among the regions based on distance is not significant. This situation occurs because the distance between two adjacent regions is not necessarily associated with lower transport costs. In contrast, regions that are far from each other may have lower transportation costs because they are connected with a good transportation network.

The role of the transportation networks in support of trade is also found in Spain. AlamaSabater et al. (2012) found that transport connectivity contributes to a high degree to increasing imports in neighbouring destination regions, 
probably due to the existence of business clusters, and to the fact that importers in Spain find it easier to cooperate with transportation matters than exporters do.

Also similar are the results of research in China, Hering and Poncet (2007) found that the positive contribution by market access to income disparities in China was mitigated by the heterogeneous impact of market access on income, depending on the local immigration intensity. The elasticity of market access to income was $62 \%$ higher in cities located in provinces characterized by low immigration flows.

Another interesting finding from this study is that there is a tendency for differences in the levels of per capita income between the North and the South. The result suggests that economic activity is more concentrated in the North. Economic activity tends to be pooled in the North due to the freeway network being more widely available in the North than in the South. This situation has created an economic gap between the North and the South in the western region of Java.

\section{CONCLUSION AND RECOMENDATION}

\section{Conclusion}

In the western region of Java, a significant relationship with per capita income has occurred among regions that are correlated based on their distance and ordinary roads connectivity, but the degree of interdependence is very low. On the other hand, a significant relationship with economic growth occurred among regions connected by freeways.

\section{Policy Recommendation}

This study recommends policy makers build sufficient road infrastructure to support trade relations. The freeways that connect regions directly with their markets will make trade relations more rapid. Trade relations in turn will have a positive effect on the economic growth of the regions connected to their central market areas.

\section{REFERENCES}

Alama-Sabater, L., L. Marquez-Ramos, C. Suarez-Burguet, and J. Miguel Navarro-Azorin. 2012. Interregional Trade and Transport Connectivity. An Analysis of Spatial Dependence. Castellon Working Paper 2012/20.

Anselin, L. 1988. Spatial Econometrics: Methods and Models. Kluwer, Dordrecht.

Anselin, L. 2003. Spatial Externalities, Spatial Multipliers, and Spatial Econometrics. International Regional Science Review 26(2), 153-166.

Chen, Y. 2012. On the Four Types of Weight Functions for Spatial Contiguity Matrix. Letter Spatial Resource Science 5,65-72.

Dixit, A. K. and V. D. Norman. 1980. Theory of International Trade. Cambridge, Cambridge University Press.

Feenstra, R. C. and A. M. Taylor. 2011. International Economics. Second Edition. New York, Worth Publisher.

Fischer, M. M. and J. Wang. 2011. Spatial Data Analysis. Models, Methods, and Techniques. Heidelberg, Springer.

Fujita, M., P. Krugman, and A. J. Venables. 1999. The Spatial Economy: Cities, Regions and International Trade. Cambridge. The MIT Press.

Hering, L. and S. Poncet. 2007. Economic Geography, Spatial Dependence, and Income Inequality in China. CEPII Working Paper 2007-22.

Ho, C. Y. and D. Li. 2010. Spatial Dependence and Divergence across Chinese Cities. Review of Development Economics 14(2),386403.

Krugman, P., 1991, Increasing Returns and Economic Geography. Journal of Political Economy 99(3),483-499.

LeSage. J. P. 1997. Regression Analysis of Spatial Data. Regional Analysis and Policy 27(2),83-94. 